\title{
Educação (a distância) desterritorializada: uma proposta para a formação de docentes online ${ }^{1}$
}

Elmara Pereira de Souza - Universidade Federal da Bahia, elmarasouza@gmail.com

Eduardo David de Oliveira - Universidade Federal da Bahia, afroduda@gmail.com

\begin{abstract}
Resumo. Esse artigo apresenta a proposta da educação (a distância) desterritorializada, compreendida como a educação que resiste às políticas públicas impostas, que aproveita as brechas para produzir singularidades, que resiste aos fluxos instituídos da educação a distância oficial. Os fundamentos da investigação encontram-se nos pressupostos teóricos de Gilles Deleuze e Felix Guattari, em especial nos conceitos de agenciamento, comunicação transversal e desterritorialização. A formação de docentes online em ambiente virtual de aprendizagem, na perspectiva da educação (a distância) desterritorializada, deve ser pensada como um processo próprio da cibercultura, vinculada à ética do coletivo, do acontecimento, da comunicação transversal, do agenciamento do desejo e da singularização.
\end{abstract}

Palavras-chave: Educação (a distância) desterritorializada. Formação de docentes online. Ambiente virtual de aprendizagem.

\section{Deterritorialized (distance) education: a proposal for online teacher training}

Abstract. This paper presents the proposal of deterritorialized (distance) education, understood as the education that resists the imposed policies, that exploits the gaps to produce singularities, which resists the flow established distance education officer. The foundations of research are the theoretical assumptions of Gilles Deleuze and Felix Guattari, in particular the concepts of agency, cross communication and deterritorialization. Online teacher training in a virtual learning environment from the perspective of deterritorialized (distance) education should be thought of as a process which is inherent in cyberculture, which is linked to the ethics of the collective, of the happening, of cross communication, of the desire assemblage and of singularization.

Keywords: Deterritorialized (distance) education. Online teacher training. Virtual learning environment.

\section{Território, desterritorialização e reterritorialização}

No contexto informacional e comunicacional da contemporaneidade, a educação online assenta nas tecnologias digitais em rede numerosas possibilidades de difusão e produção do conhecimento, projetando em suas propostas curriculares a utilização dessas tecnologias no desenvolvimento das atividades de ensino-aprendizagem. Atualmente muitas instituições de ensino estão implantando a educação online como forma de ampliar a abrangência dos seus programas.

Porém, ainda se observa, em muitos programas de formação de professores, a utilização das plataformas de aprendizagem, dos espaços interativos na perspectiva das mídias de massa, desconsiderando o potencial dessas tecnologias no processo ensinoaprendizagem. Com os meios de comunicação de massa, a subjetividade ${ }^{2}$ é perpassada por jogos semióticos, que resultam em balizamentos do pensar, do agir econômico, político e interpessoal (OLIVEIRA, 2006).

É evidente que a utilização dos espaços virtuais de aprendizagem na formação de professores modifica o domínio sobre o fazer docente praticado na modalidade presencial. Não se trata aqui de dicotomizar, colocando de um lado a educação presencial e, do outro, a educação a distância, mas de pensar a educação online como 
um campo rico de possibilidades e potencialidades. A educação presencial é um território conhecido. Para que a educação a distância possa se constituir como outro território, faz-se necessário uma desterritorialização dessa educação constituída utilizando vetores de saída, vetores de crítica, por meio das linhas de fuga, onde se encontram os desejos (DELEUZE; GUATTARI, 2009, 2007; GUATTARI; ROLNIK, 2010) para que as reterritorializações possam acontecer, e a educação a distância, utilizando as tecnologias digitais, possa ser constituída como um novo território, um território que promova afetos ${ }^{3}$, em especial afetos-alegrias e o aumento da potência de agir das pessoas. As linhas de fuga não indicam fugir da situação, mas "fazer fugir", explorar os possíveis espaços de desterritorialização.

Para que o movimento de desterritorialização e reterritorialização aconteça, é preciso encontrar linhas de fuga, linhas de desejo (que não são lineares e que atravessam o território "educação") para que agenciamentos (diferentes dos que encontramos na sala de aula presencial) possam acontecer e criar outros ritmos, outras possibilidades da educação online se constituir como território/espaço de criação, de autoria e aberto a novas desterritorializações e reterritorializações.

Neste estudo, utiliza-se os conceitos de território, desterritorialização e reterritorialização de Deleuze e Guattari (2009) e Deleuze (1988, 1997), para construir a proposta da educação (a distância) desterritorializada para a formação de docentes online em AVA.

Deleuze, em entrevista (vídeo Abecedário de Gilles Deleuze, 1997), fala sobre o conceito de desterritorialização. Segundo ele,

\begin{abstract}
Precisamos, às vezes, inventar uma palavra bárbara para dar conta de uma noção com pretensão nova. A noção com pretensão nova é que não há território sem um vetor de saída do território e não há saída do território, ou seja, desterritorialização, sem, ao mesmo tempo, um esforço para se reterritorializar em outra parte.
\end{abstract}

Segundo Zourabichvili (2009), o termo "desterritorialização" é um neologismo surgido no livro Anti-Édipo e se difundiu amplamente nas ciências humanas. Esse conceito foi desdobrado pelos autores nos livros Mil Platôs (2009) e O que é Filosofia (2009a). Com base nesse conceito, nos propomos a pensar questões do território “educação a distância”, a desterritorialização e a reterritorialização dessa modalidade de ensino, segundo os vetores de saída, acontecimentos e agenciamentos na formação dos docentes online em ambiente virtual de aprendizagem.

Nesse estudo, o conceito de ambiente virtual de aprendizagem assume novos contornos e o AVA é definido como um dispositivo de produção de subjetividade, que é a combinação do visível, invisível, dizível, do silêncio, das forças, das relações e linhas que conectam as pessoas que o habitam.

Para compreender a significação da educação (a distância) desterritorializada é necessário fazer referência a três elementos: território, terra e reterritorialização.

Inspirado antes na etologia do que na política, o conceito de território decerto implica o espaço, mas não consiste na delimitação objetiva de um lugar geográfico. O valor do território é existencial: ele circunscreve, para cada um, o campo do familiar e do vinculante, marca as distâncias em relação a outrem e protege do caos. O investimento íntimo do espaço e do tempo implica essa delimitação, inseparavelmente material e afetiva (fronteiras problemáticas de minha "potência"). O traçado territorial distribui um fora e um dentro, ora passivamente percebido como o contorno intocável da experiência (pontos de angústia, de vergonha, de inibição), ora perseguido ativamente como sua linha de fuga, portanto como zona de experiência (ZOURABICHVILI, 2009, p. 23). 
Distingue-se a desterritorialização relativa, que significa mudar de território, ou seja, reterritorializar de outra forma, da desterritorialização absoluta, do nômade ${ }^{4}$, que implica viver sobre uma linha de fuga para criar um novo território, o momento do desejo, o devir.

O nômade desconstrói o que está posto e faz brotar multiplicidades. O nomadismo tem como principal potencialidade o movimento de gerar desterritorializações. Nesse sentido, existem práticas e modos de vida que podem ultrapassar estruturas constituídas e serem resistentes a elas (DELEUZE; GUATTARI, 2008).

Para os autores é a expressividade, e não a funcionalidade, que explica a formação do território. O território faz emergir ritmos próprios que não indicam identidade e garantem a formação daquele domínio. A expressão que emerge do território formando-o não pode ser tomada como o pertencimento de algo que tem existência prévia ao ato expressivo. “O território é antes de tudo lugar de passagem” (id, p. 132) e a relação entre quem habita o território e o próprio território é de invenção recíproca e não de adaptação. Nesse sentido a habitação no AVA pode ser de criação, de autoria e não de adaptação a propostas pré-fixadas, determinadas, impostas. Na formação de docentes online compreendemos ser fundamental proporcionar possibilidades para que o professor invente, para que ele possa se autorizar a criar espaços coletivos para discussões e produção de conhecimentos.

Sabemos que em toda práxis há uma finalidade que pode ser, por um lado, vinculada aos interesses dominantes, repressora e, por outro, pode proporcionar criação, singularidade. A práxis pode ser alienante, dominante, mas também pode ser libertadora, ética. Compreende-se que há esses caminhos antagônicos, mas para além dessas dicotomias, de bem e mal, a proposta é de um caminho baseado na criação de novos territórios para a educação a distância, para a formação de docentes online fundamentados na ética, na produção de subjetividade autorreferente ${ }^{5}$, na experiência enquanto agenciadora dos desejos.

Criar um novo território é se aventurar, é trilhar caminhos diferentes, é se abrir a novos agenciamentos, é sair do espaço sedentário, estriado, é encontrar através da expressividade, das linhas de fuga outras e novas possibilidades. Essas linhas podem ser pontos de singularidades e possibilidade criativa, além de poder ser as que desterritorializam e reterritorializam criando, a partir do nomadismo, novos mundos, nova “vida”. Deleuze e Guattari (1997, p. 129) dizem que “é nômade todo processo (político, coletivo, individual, psíquico etc.) que traça uma linha de fuga aos aparelhos do Estado sedentário e de seus subprodutos”. Há uma grande diferença entre o espaço sedentário e o nômade: "o espaço sedentário é estriado, cercado por muros e caminhos entre os cercados, enquanto o espaço nômade é marcado apenas por "traços" que se apagam e se deslocam com o trajeto" (id, p.43).

Compreende-se que nas margens estão abertas as possibilidades, são os contornos e as dobras que nos permitem olhar e articular com o fora, com os espaços onde os afetos e os perceptos se mostram e emerge a singularidade na heterogeneidade. Considerando a educação a distância como um território constituído, espaço sedentário cheio de muros e, considerando que todo território é lugar de passagem, a proposta é trazer possibilidades de busca por linhas de fuga para repensar a EaD e criar a partir de um espaço nômade, deslocamentos de sentido e novas possibilidades de utilização dos espaços virtuais de aprendizagem. A partir desse estudo, é proposto, portanto, uma micropolítica do afeto, da percepção, do diálogo e da autoria para/na formação dos docentes online em AVA.

Sabemos dos desafios de tecer esses caminhos de fuga numa educação a 
distância em que já está posto o que deve ser aprendido e ensinado ou no processo de formação em que já estão definidos os currículos de formação do docente online. Buscamos algumas brechas para uma formação mais ampla, onde o desejo possa ser construído, as singularidades possam emergir na multiplicidade, os afetos-alegrias possam ser constantes e a subjetividade autorreferente também possa ser produzida. Foucault (1991, p.91) já dizia que “onde há poder há resistência”, ou seja, mesmo em ambientes fechados, tradicionais de formação, pode-se buscar possibilidades de pequenas desterritorializações, de traçar linha de fuga e criar espaços abertos e dialógicos onde possam fomentar as singularizações na formação de professores para atuarem na educação online.

\begin{abstract}
Este é um processo aberto, para o qual não há receitas e nem programas. O que pode fazer um educador incomodado com a serialização do processo de subjetivação é instalar-se em seu meio, à espreita dos acontecimentos e dos buracos, para agir neste fluxo, provocando pequenas desterritorializações no interior mesmo do território. Fazer vazar singularizações onde só há subjetivação. Não é um processo fácil, mas é apaixonante e desafiador (GALLO, 2010, p.241).
\end{abstract}

Esse desafio é sedutor. A partir da experiência na educação online, do desafio da desconstrução da própria $\mathrm{EaD}$ e, compreendendo que pesquisar é criar, é proposto um outro olhar para a formação de docentes online e para a EaD, a desterritorialização e reterritorialização dessa modalidade de ensino. Salienta-se que a desterritorialização não é o ponto de chegada, mas faz parte de um processo de criação de novos territórios.

\title{
2. Educação (a distância) desterritorializada: uma proposta
}

A formação docente, proposta nesse estudo, está em consonância com a proposta de Gallo (2008) de uma educação menor, baseado no conceito deleuzo-guattariano de literatura menor explicitado no livro Kafka - Por uma literatura menor (1977). Utilizando esse conceito na área educacional e, tomando emprestado para a educação a distância, podemos considerar uma educação maior aquela oficial, já instituída, sedimentada, aquela dos projetos, das políticas públicas pensadas por poucos e imposta para muitos. A educação menor, chamada nesse estudo de educação (a distância) desterritorializada, é como uma máquina de resistência ou máquina de guerra e não aparelho de Estado, é aquela micropolítica que resiste às políticas públicas impostas, que aproveita as brechas, os espaços vazios para trabalhar as singularidades.

Máquina de guerra, segundo Deleuze e Guattari (2008, p. 97) é “um fluxo de guerra absoluta que escoa de um polo ofensivo a um polo defensivo e não é marcado senão por quanta (forças materiais e psíquicas que são como que disponibilidades nominais da guerra)”. O conceito de máquina de guerra desestabiliza a máquina estatal, no caso desse estudo, a educação a distância oficial, massificadora. A máquina é uma construção marcada por fluxos de desejo, de interesses, conexões, por agenciamentos compostos de linhas de vários tipos: as linhas molares, duras, que amarram e levam a segmentações e as linhas moleculares, que não se deixam aprisionar, as linhas de fuga. São estas linhas que fazem a máquina de guerra, com sua multiplicidade e seus devires.

Como conceber a formação de docentes online em AVA na perspectiva da educação (a distância) desterritorializada? Como implementar uma educação (a distância) desterritorializada dentro de uma educação a distância maior, totalitária, impositiva?

As políticas públicas voltadas para a educação a distância impõem regras, definem projetos e propostas homogêneas, desconsiderando, muitas vezes, as peculiaridades da modalidade, da região, da cultura, das pessoas, desconsiderando a 
heterogeneidade, a multiplicidade, a singularidade. A educação (a distância) desterritorializada resiste aos fluxos instituídos da $\mathrm{EaD}$ oficial, pois é rizomática e não está preocupada com a instauração de "nenhuma falsa totalidade” (GALLO, 2008, p. 68). Não interessa à educação (a distância) desterritorializada criar modelos, propor caminhos, impor soluções, o que importa é criar conexões, redes, "rizomatizar", singularizar.

Na educação (a distância) desterritorializada, os atos são sempre coletivos, as singularizações são coletivas, a partir da adesão de cada singularidade e conectam e interconectam gerando multiplicidades. As interações são em rede, como o rizoma que não tem início nem fim, mas intensidades no meio, no entre. "Não há sujeitos, não há objetos, não há ações centradas em um ou outro; há projetos, acontecimentos, individuações sem sujeitos. Todo projeto é coletivo. Todo valor é coletivo. Todo fracasso também” (GALLO, 2008, p; 69).

Por sua ação de resistência aos territórios constituídos da educação a distância oficial que utiliza mídias de massa ou mídias interativas na perspectiva das mídias de massa, propõe produzir subjetividade a partir de uma ética do coletivo, do acontecimento, da autoria, do diálogo, do respeito ao outro, do afeto. Para que a educação (a distância) desterritorializada ultrapasse a utopia (como negação da realidade) e passe a ser, “desde a dimensão do desejo, referência de percurso", (OLIVEIRA, 2006, p. 47), linha de fuga do território EaD, compreende-se como fundamental a utilização de estratégias que potencializem a produção de subjetividade ética, a produção de subjetividade autorreferente, as linhas dos afetos-alegrias.

Assim como Gallo (2008), sabemos que, ao propor a formação de professores de cursos online na perspectiva da educação (a distância) desterritorializada, não estamos imunes a riscos. A luta da minoria não é nada fácil. Corre-se o risco de se reterritorializar na educação a distância maior, desfazendo seu potencial crítico, tornando-se outra vez máquina de Estado. É preciso resistir com a convicção de que poderemos criar poros nesse terreno cristalizado e que sempre haverá brechas, fissuras e caminhos de fuga para novas desterritorializações.

Para que seja introduzida a educação (a distância) desterritorializada na instituição é necessária uma prática educativa ético-estético-política para que ela possa se configurar efetivamente como uma modalidade educativa de qualidade e que cumpra os seus objetivos. É importante que a formação de professores para atuar na educação (a distância) desterritorializada seja prioridade nos projetos políticos pedagógicos das instituições de ensino.

Para buscar linhas de fuga e possíveis desterritorializações na educação a distância oficial, assumimos o desafio de pensar em como agenciar desejos na formação de professores de cursos online em ambiente virtual de aprendizagem. Deleuze diz que agenciamento de desejo marca que o desejo jamais é uma determinação "natural", nem "espontânea".

\subsection{Agenciamentos de desejo}

No sistema capitalista ou no Capitalismo Mundial Integrado ${ }^{6}$ (CMI), a produção de subjetividade e a manipulação do desejo é uma arma poderosíssima na competição pelo controle e domínio do mercado (OLIVEIRA, 2006). Para compreender melhor essa característica do mundo globalizado é preciso levar em consideração não só a categoria econômica, mas também, as categorias culturais de produção de subjetividade. A análise da produção de subjetividade em ambiente virtual de aprendizagem passa por uma análise semiótica de ressignificação da educação a distância e se insere na perspectiva da busca por linhas de fuga que nos permitam fazer a crítica à EaD tradicional e propor 
a concepção da educação (a distância) desterritorializada.

\begin{abstract}
Na era dos meios de comunicação de massa a subjetividade é perpassada por jogos semióticos que resultam em balizamentos do pensar, do agir econômico, político e interpessoal. Interferindo nos domínios mais íntimos da vida privada. Os Meios de Comunicação Social modulam vontades, desejos, angústias e anseios, mobilizando diversas formas de práxis e construindo hegemonias, obtendo com isso o aval ideológico para a falácia da existência do sistema único de valor (OLIVEIRA, 2006, p. 44).
\end{abstract}

A manipulação do desejo tornou-se uma arma poderosa nas mãos do capital na competição pelo controle do domínio dos mercados (OLIVEIRA, 2006). "Produzem-se agora desejos na forma de signos e não de objetos materiais. O consumo é menos alguma coisa real e mais propriamente um signo, porque é o signo que se deseja" (VILLAÇA; GÓES, 1998, p. 50).

As políticas públicas de formação de professores em ambiente virtual de aprendizagem quase sempre são homogêneas, não favorecem a produção de subjetividade singular, autorreferente. Elas contemplam as subjetividades da norma, mercadológica, que chamamos de legisubjetividade ${ }^{7}$.

A produção da legisubjetividade é uma realidade na formação dos docentes online. O sistema cria uma realidade que mobiliza as pessoas predispondo-as ao consumo de cursos, a busca por formação por uma necessidade de se manter atualizado, de se inserir nessa modalidade de ensino ou para obtenção de certificação. A formalidade, a obrigatoriedade, a imposição de formação provocam a produção da legisubjetividade e são castradoras e não promotoras do desejo. Ao estudarmos a formação de docentes online encontramos subjetividades (re)produzidas a partir da necessidade imposta de qualificação, do consumo da (in)formação.

Segundo Oliveira (2006, p. 45) as consequências desse processo são

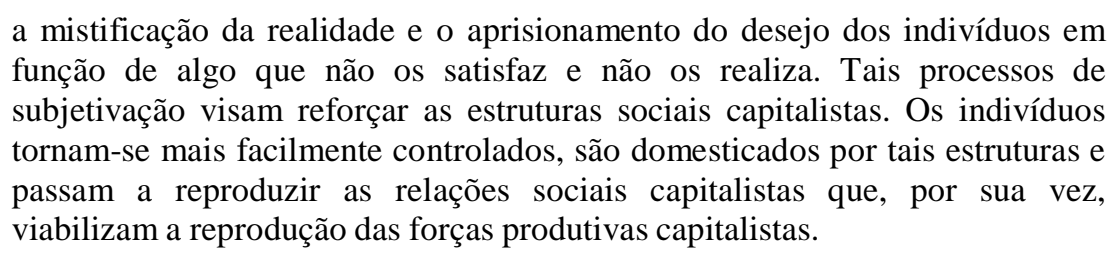

Compreende-se que todo desejo procede de um encontro que é arquitetado, construído. O desejo não é conservador, ele é produtivo, revolucionário e realiza-se sempre. O desejo não é espontâneo, só há desejo agenciado, maquinado. Porém, para que esse desejo possa realizar-se produtivamente numa máquina social é necessário que as condições socioculturais engendrem modos de subjetivação que favoreçam as condições para a produção do desejo. Os agenciamentos do desejo formam uma espécie de rizoma "com seus saltos, desvios, passagens subterrâneas, caules, desembocaduras, traços, buracos etc.” (DELEUZE; GUATTARI, 1997, p.86). Mas, no outro lado, os agenciamentos sedentários fazem ressoar os buracos conjuntamente, acabam com as linhas de fuga, "subordinam a operação tecnológica ao modelo do trabalho, impõem às conexões todo um regime de conjunções arborescentes” (id, p.87).

Os processos de formação de professores nos colocam diante de uma realidade que desestimula, que atrofia o desejo. As instituições de ensino ao proporem formação para docentes online voltada para aspectos técnicos, impondo o currículo, coloca o desejo do professor num patamar quase inexistente.

Se pensarmos na formação em AVA, consideramos que o espaço virtual, por um lado, pode ser castrador do desejo, mas, por outro, também pode ser sedutor. Ele pode ser inibidor do desejo quando, por exemplo, restringe a participação por falta do acesso á própria tecnologia, por elucidar os limites pessoais de uso dessa tecnologia, por expor, 
em certa medida, as pessoas, por proporcionar afetos-tristezas. Porém, ele pode ser sedutor quanto provoca uma busca por novos conhecimentos, quando favorece processos de produção coletiva, quando proporciona encontros, afetos-alegrias, quando favorece a participação mesmo que haja distância física entre os atores do processo educacional, quando proporciona a utilização de um espaço contemporâneo e potencialmente rico para a formação.

Podemos pensar em algumas estratégias que podem favorecer o desejo pelo conhecimento, pelo saber na formação de docentes online: (i) o projeto coletivo que considere a experiência, a história de vida do professor; (ii) o design da plataforma de aprendizagem; (iii) a proposição do ambiente; (iv) a proposta metodológica e pedagógica que favoreça a criação, que proporcione espaços abertos para a autoria, que considere o desejo coletivo; (v) a forma e a qualidade da interação, o favorecimento ao diálogo; (v) a linguagem sedutora utilizada pelos professores; (vii) a qualidade do material disponibilizado; (viii) as políticas públicas que favorecem a participação do professor disponibilizando tempo para as interações; (ix) espaços abertos que favoreçam a polifonia, a multiplicidade, os afetos-alegres, podem ser pensados no sentido de agenciar o desejo.

As linhas dos afetos no AVA que provocam a desterritorialização também podem ser outra possibilidade de agenciamento do desejo. $\mathrm{O}$ afeto é um vetor capaz de agenciar. As linhas do afeto atuam como fluxo no encontro com outros corpos. No AVA os corpos se encontram virtualmente e podem construir redes. A construção das redes produz o plano de imanência. Deleuze (2002) diz que é no plano de imanência que estão todos os corpos, almas e indivíduos e é o plano que os corpos, potência de afetar e ser afetado, percebem e, ao mesmo tempo, compõem a realidade.

Compreende-se que é muito mais difícil, mas possível, planejar, organizar, criar, implementar um espaço virtual formativo, um ambiente virtual de aprendizagem aberto à criação, que pense a singularidade, a diferença, que agencie o desejo coletivo, do que um curso que pense a homogeneização, a massificação. As políticas públicas do virtual, da educação a distância massificadora produzem cursos homogeneizantes, redutores e que, em geral, não conseguem agenciar o desejo pela construção do conhecimento vinculado à ética, mas apenas agenciar o desejo da burocracia, da legalidade, do consumo, produzindo e sendo produzido pela legisubjetividade.

\subsection{Agenciamento maquínico e agenciamento coletivo de enunciação}

Segundo Deleuze e Guattari (2007, p. 31) um agenciamento remete a um "estado preciso de mistura de corpos em uma sociedade, compreendendo todas as atrações e repulsões, as simpatias e as antipatias, as alterações, as alianças, as penetrações e expansões que afetam os corpos de todos os tipos, uns em relação aos outros”. Os agenciamentos coletivos tanto são maquínicos quanto de enunciação.

Na educação a distância, observa-se tanto o agenciamento maquínico, na relação homem/máquina, quanto o agenciamento de enunciação, na relação homem/escrita no espaço virtual. Deleuze e Guattari (2007, p. 31) dizem que no aspecto semiótico “o agenciamento não remete a uma produtividade de linguagem, mas a regimes de signos, a uma máquina de expressão cujas variáveis determinam o uso dos elementos da língua”.

A expressão refere-se ao conteúdo sem representá-lo ou descrevê-lo, mas intervêm nele. $\mathrm{O}$ agenciamento é comunicação direta sem mediação, sem subordinação ou hierarquia. O agenciamento familiar, da mídia, do trabalho são exemplos de agenciamento coletivo de enunciação. $\mathrm{O}$ agenciamento não diz respeito nem a uma entidade individualizada, nem a uma entidade coletiva, social predeterminada. Ele opera 
por implicação entre processos, movimentos, fluxos heterogêneos.

No ambiente virtual de aprendizagem para a formação de docentes online os agenciamentos coletivos podem produzir fluxos: fluxos dialógicos, fluxos afetivos, fluxos atitudinais.

Portanto, as subjetividades no ambiente virtual podem ser produzidas por agenciamentos de enunciação. Axt (2006) afirma que há uma multiplicidade de posições enunciativas, potencializando (pelos cruzamentos entre esses heterogêneos) os modos de enunciar; em uma palavra, há multiplicidade de natureza dialógica instaurando processos de produção de sentidos, potencializando processos de criação e de autoria. $\mathrm{O}$ sentido é potencialmente infinito e só se atualiza no contato com outro sentido (o sentido do outro). O conceito de sentido na compreensão bakhtiniana reconhece que não há um "sentido em si", pois o sentido se situa sempre entre os sentidos, elo de uma cadeia do sentido (BAKHTIN, 2000). Podemos dizer "(já numa ótica mais deleuziana), que da heterogeneidade e das conexões entre os heterogêneos é que emergem linhas de criação, de invenção” (AXT, 2006, p. 265).

Quando Deleuze e Guattari pensam o conceito de agenciamento coletivo de enunciação, retomam a noção de discurso indireto de Bakhtin (2000) enfatizando que há muitas vozes em uma voz, pois todo discurso é indireto. Esse caráter coletivo da linguagem indica que mesmo em uma escrita individual há muitas vozes em diálogo. No AVA essas vozes se misturam e se mostram em cada enunciado, em cada silêncio, em cada atitude.

O conceito de agenciamento maquínico põe em conexão fluxos, processos, criam formas, estabelece relações de comunicação sem determinismo, capazes de gerar diferentes produtos e a heterogênese da sua própria máquina (KASTRUP, 2008), diferente da relação mecânica que se dá entre elementos prévios e que se forem observadas as mesmas relações e os mesmos elementos obteremos sempre o mesmo produto.

Continuando a refletir sobre a construção da educação (a distância) desterritorializada, pensemos em outras possibilidades de comunicação em AVA para a formação de docentes online.

\subsection{Comunicação transversal}

Outra característica proposta para a educação (a distância) desterritorializada é a transversalidade comunicacional (GUATTARI, 2004, DELEUZE, 1988). O conceito de transversalidade foi proposto por Guattari no contexto da análise institucional dos anos 60 , servindo-lhe para pensar o que ocorrera em maio de $68^{8}$. A transversalidade é o movimento de abertura comunicacional, de desestabilização dos eixos dominantes de organização da comunicação nas instituições: eixo vertical de hierarquização da comunicação entre os diferentes e o eixo horizontal de homogeneização da comunicação entre os iguais (PASSOS e BARROS, 2010). Deleuze traz à tona esse conceito no livro Proust e os signos (1998) quando analisa a posição do narrador em relação à obra afirmando que o narrador se relaciona com a obra numa dimensão de transversalidade comunicacional, ou seja, como máquina catalisadora dos afetos.

Portanto, vislumbramos um terceiro eixo na comunicação em AVA que cruza os eixos vertical e horizontal. O eixo vertical, hierárquico é muito comum nos cursos a distância para a formação de docente online. O plano da tranversalidade 
saber, o saber que o outro tem e que pode me transmitir), mas experimenta o 
entre os diferentes nós de uma rede de enunciação da qual emerge, como seu efeito, um mundo que pode ser compartilhado pelos sujeitos (PASSOS; EIRADO, 2010, p.117).

A comunicação transversal, proposta para a educação (a distância) desterritorializada, tem como enfoque a multivocalidade, o favorecimento à expressão da diversidade de sentidos, a polifonia - entrecruzamento de vozes na perspectiva do aumento do grau de abertura comunicacional.

A transversalidade como princípio metodológico em AVA propõe à abertura aos diversos pontos de vista. A comunicação nos ambientes virtuais para formação de docentes online é, em geral, verticalizada e as instâncias de poder presentes no ambiente, em certa medida, não favorecem o diálogo, não agenciam o desejo, impondo o que deve ser aprendido, ensinado, discutido, favorecendo, em certa medida, a ação do voyeur, do observador, daquele que nada produz, mas consome o que é produzido no AVA.

Indicando a comunicação transversal em AVA estamos tratando da escuta e da vivência das singularidades, das diferenças, em detrimento do senso comum e/ou do consenso. A comunicação transversal pode catalisar os afetos, promovendo o agenciamento do desejo e produzindo, também, subjetividade autorreferente.

\begin{abstract}
Eis então o que seria necessário fazer: instalar-se sobre um estrato, experimentar as oportunidades que ele nos oferece, buscar aí um lugar favorável, eventuais movimentos de desterritorialização, linhas de fuga possíveis, vivenciá-las, assegurar aqui e ali conjunções de fluxos, experimentar segmento por segmento dos contínuos de intensidades, e ter sempre um pequeno pedaço de uma nova terra. [...] Estamos numa formação social; ver primeiramente, como ela é estratificada para nós. Em nós, no lugar onde estamos; ir dos estratos ao agenciamento mais profundo em que estamos envolvidos; fazer com que o agenciamento oscile delicadamente, faze-lo passar ao lado do plano de consistência. (DELEUZE; GUATTARI, 2008, p. 24).
\end{abstract}

É na busca desse lugar favorável, a partir de pequenas desterritorializações e reterritorializações que propomos a formação de docente online na perspectiva de uma educação (a distância) desterritorializada. Agenciar o desejo, experimentar a comunicação transversal, propor micropolíticas de formação docente que encontre ressonância na criação, na produção coletiva, na autoria, na práxis, na construção de novos sentidos para a educação online: essa é a proposta.

\title{
Notas
}

${ }^{1}$ Artigo elaborado a partir da Tese de Doutorado intitulada “Cartografia da Produção de subjetividade em ambiente virtual de aprendizagem para a formação de docentes online”, de Elmara Pereira de Souza, defendida em 20 de março de 2013, no Doutorado Multi-institucional e Multidisciplinar em Difusão do Conhecimento da Universidade Federal da Bahia.

2 A subjetividade é um processo contínuo e acontece de acordo com a configuração sócio-histórica em que se situa, desvinculando-se dos domínios da representação. À luz dos pressupostos teóricos deleuzoguattarianos, compreende-se que a subjetividade é fabricada e modelada no registro do social, mas vivida em sua existência singular.

${ }^{3}$ Afetos, segundo Espinosa (2009), são as afecções do corpo pelas quais a potência de agir é aumentada ou diminuída, favorecida ou impedida. Os afetos que aumentam a potência de agir são chamados alegrias. Os afetos que diminuem a potência de existir são as tristezas.

${ }^{4}$ Segundo Deleuze (1998), o nômade é o homem da terra, o homem da desterritorialização - ainda que ele seja também aquele que não se move, que permanece agarrado ao meio, deserto ou estepe.

${ }^{5}$ Subjetividade autorreferente, neste estudo, é entendida como a subjetividade que não é produzida pelas mídias de massa ou belos aparelhos de efstado dout seja é a subjetivjdade singular. 
${ }^{6}$ O termo CMI foi criado por Félix Guattari para dizer que há uma forte tendência do capitalismo 
tentáculos reterritorializantes. O acréscimo do sufixo "ismo" ao termo “capitalista” produziu um neologismo que traduz a noção de que a cartografia subjetiva do terceiro mundo e de países exintegrantes do bloco socialista do leste europeu seguem padrões semelhantes de constituição dos países industrializados da vanguarda capitalista. (GUATTARI; ROLNIK, 2010).

7 Termo criado, nesse estudo, para indicar a subjetividade da legalidade, da norma, do consumo em oposição à subjetividade plural, autorreferente, que contempla a singularidade.

${ }^{8}$ Em maio de 1968, houve uma grande onda de protestos na França, que teve início com manifestações estudantis para pedir reformas no setor educacional. O movimento cresceu e evoluiu para uma greve de trabalhadores, que balançou o governo do então presidente da França, Charles De Gaulle. Os universitários se uniram aos operários e promoveram a maior greve geral da Europa. Isso enfraqueceu politicamente o general De Gaulle, que renunciou um ano depois. Alguns filósofos e historiadores afirmaram que a rebelião ocorrida em maio de 68 foi o acontecimento revolucionário mais importante do século XX, porque não se deveu a uma camada restrita da população, como trabalhadores ou minorias, mas a uma insurreição popular que superou barreiras étnicas, culturais, de idade e de classe.

\section{Referências Bibliográficas}

AXT, M. Comunidades Virtuais de Aprendizagem e interação dialógica: do corpo, do rosto e do olhar. Revista Filosofia UNISINOS. Set/dez 2006. p. 256 a 268. Disponível em http://www.lelic.ufrgs.br/portal/images/stories/comunidadeaxt.pdf Acesso em 15 de fevereiro de 2010.

BAKHTIN, M. Estética da Criação Verbal. 4. ed. São Paulo: Martins fontes, 2000.

DELEUZE, G. Diferença e repetição. Trad. Luiz Orlandi e Roberto Machado. Rio de Janeiro: Graal, 1988.

DELEUZE, G. O abecedário de Gilles Deleuze. Vídeo. Divulgado no Brasil, pela TV Escola, Ministério da Educação. Tradução e Legendas: Raccord. 1997.

DELEUZE, G. Proust e os signos. Rio de Janeiro: Forense Universitária, 1998.

DELEUZE, G. Espinosa - filosofia prática. São Paulo: Editora, 2002.

ESPINOSA, B. Ética. Belo Horizonte. Autêntica, 2009.

FOUCAULT, M. Vigiar e punir: história da violência nas prisões. 8. ed. Petrópolis: Vozes, 1991.

GALLO, S. Deleuze e a educação. Belo Horizonte: Autêntica, 2008.

GALLO, S. Educação: entre a subjetivação e a singularidade. Revista Educação. UFSM. V. 35. n. 2, p. 229-244, maio/ago. 2010 Disponível em: http://www.ufsm.br/revistaeducacao Acesso em 04 de fevereiro de 2011.

GUATTARI, F., ROLNIK, S. Micropolítica: cartografias do desejo. Editora Vozes: Petrópolis, 2010.

KASTRUP, V. A cognição contemporânea e a aprendizagem inventiva. In KASTRUP, V; TEDESCO, S; PASSOS, E. Políticas da Cognição. Porto Alegre, Sulina, 2008.

DELEUZE, G.; GUATTARI, F. Kafka: por uma literatura menor. Rio de Janeiro. Ed. Imago, 1977.

DELEUZE, G.; GUATTARI, F. Mil Platôs. V 5. Rio de Janeiro. Ed. 34. 1997.

DELEUZE, G.; GUATTARI, F. Mil platôs. V.2. Rio de Janeiro: Ed. 34. 2007.

DELEUZE, G.; GUATTARI, F. Mil Platôs. V 3. Rio de Janeiro. Ed. 34. 2008.

DELEUZE, G.; GUATTARI, F. Mil Platôs. V 1. Rio de Janeiro. Ed. 34. 2009.

DELEUZE, G.; GUATTARI, F. O que é filosofia?. Rio de Janeiro. Editora 34. 2009 a.

OLIVEIRA, D. (org) Ética e movimentos sociais populares: práxis, subjetividade e libertação. Curitiba: Ed. Gráfica Popular, 2006.

PASSOS, E; BARROS, R. B. A cartografia como método de pesquisa-intervenção. In PASSOS, E; KASTRUP, V; ESCÓSSIA, L (org) Pistas do método da cartografia - pesquisa intervenção e produção de subjetividade. Porto Alegre. Ed. Sulina, 2010.

PASSOS, E; EIRADO, A. Cartografia como dissolução do ponto de vista do observador. In PASSOS, E; KASTRUP, V; ESCÓSSIA, L (org) Pistas do método da cartografia - pesquisa intervenção e produção de subjetividade. Porto Alegre. Ed. Sulina, 2010. VILLAÇA, N.; GÓES, F. Em nome do corpo. Rio de Janeiro: Ed. Artemídia Rocco, 1998. ZOURABICHVILI, F. O Vocabulário de Deleuze. Rio de Janeiro. Relume Dumará, 2009. 